\title{
Perception and short-term storage in dichotic listening performance'
}

\author{
JAMES INGLIS AND CAROL L, TANSEY \\ TEMPLE UNIVERSITY MEDICAL SCHOOL
}

Alternative hypotheses have been put forward to account for order-effect in dichotic listening performance. One of these involves a distinction between perceptual and shortterm storage mechanisms, the other requires only different storage mechanisms. If the distinction between perception and storage may be regarded as related to the difference between activity traces and structural traces, then the repeated digit series technique devised by Hebb (1961) offers a means of testing these alternatives. Results suggest that a single, rather than a dual mechanism underlies order-effect in the sequential recall of simultaneous stimuli.

In the study of dichotic listening performance developed by Broadbent (1957), spoken digits are recorded on separate channels of a single magnetic tape so that different digits may be played back simultaneously to both ears. It has been found that Ss tend to recall all the digits that were read into one ear before recalling the numbers heard in the other ear and that the material recalled first in sequence contains fewer errors. Broadbent (1958) has suggested that the material recalled second in series (i.e., from the delayed channel) may have been held in some short-term store while the material recalled first (from the immediate channel) has only passed through a kind of perceptual system. Another model has also been put forward (Inglis, 1965) which seems to account for the data at least as well. In this alternative view, both half-spans have entered (different) storage systems, but the delayed half-spans have been held in store longer and have been subject to more recall interference, hence more errors appear. In Hebb's (1949) terms the former hypothesis requires only an "activity trace" to deal with material from the immediate channel while some "structural trace" might be needed for the recall of material from the delayed channel. The alternative hypothesis, however, suggests that a structural trace should underlie performance on both channels.

Both Hebb (1961) and Melton (1963) have shown that repetition of the same series of digits, of the ordinary immediate memory span type, interspersed among non-repeated series, produce cumulative learning curves of performance in young normal Ss, and hence evidence for structural trace changes.

The present investigation was designed to test the alternative hypotheses cited above, through the dichotic presentation of repeated and non-repeated spans. If cumulative improvement could be shown for all the repeated series, both immediate and delayed, this would provide evidence in support of the notion that a structural change, and hence short-term storage, underlies performance on both channels.

\section{Method}

Twenty-one right-handed Ss (six males, 18 females) between the ages of 18 and 40 (mean age 27.3 years) were tested; all were at least high-school graduates. The test material comprised two sets of 24 spans of dichotic digits with four digits per half-span. One dichotic pair was read out every $2 / 3 \mathrm{sec}$. In order to achieve better separation between channels one halfset was read by a man, the other by a girl. Every third half-span on each channel was a repeated span but the two ears heard different repeated spans simultaneously. On half the trials the Ss were instructed to recall the right ear first; on the remainder, the left ear material had to be recalled first in sequence. At the end of the test the Ss were asked if they had noticed any peculiarity in the number series; about $50 \%$ said that they had noticed some repetition, but none could be more specific.

Performance was scored in terms of the fixedorder recall criteria specified by Inglis \& Ankus (1965).

Results

Contrary to the findings of other investigators (e.g., Kimura, 1961; Dirks, 1964) the recall of material read to the right ear was not, overall, superior to the recall of left ear material. There was some evidence, however, that right and left show different effects over trials $(F=3.63, p<.01)$ and that this depends on whether they are dealing with immediate or delayed recall $(\mathrm{F}=4.39, \mathrm{p}<.01)$.

As Broadbent (1957) originally showed, the greatest significant difference $(F=126.34, p<.001)$ was found in the superior accuracy of recall of digits in the immediate versus the delayed channel. This significance held for both repeated and non-repeated spans (see Fig. 1).

The next greatest significant difference $(F=10.04$, $\mathrm{p}<.01$ ) was found between the repeated and nonrepeated series; overall, the repeated series were recalled more accurately. The effect of sequence, from the first to the last trial, was also significant $(F=6.68, \mathrm{p}<.01)$.

The "learning effect" for the repeated digits was, in fact, significantly greater $(F=2.92, p<.01)$ than for the non-repeated spans (see Fig. 1), thus confirming 


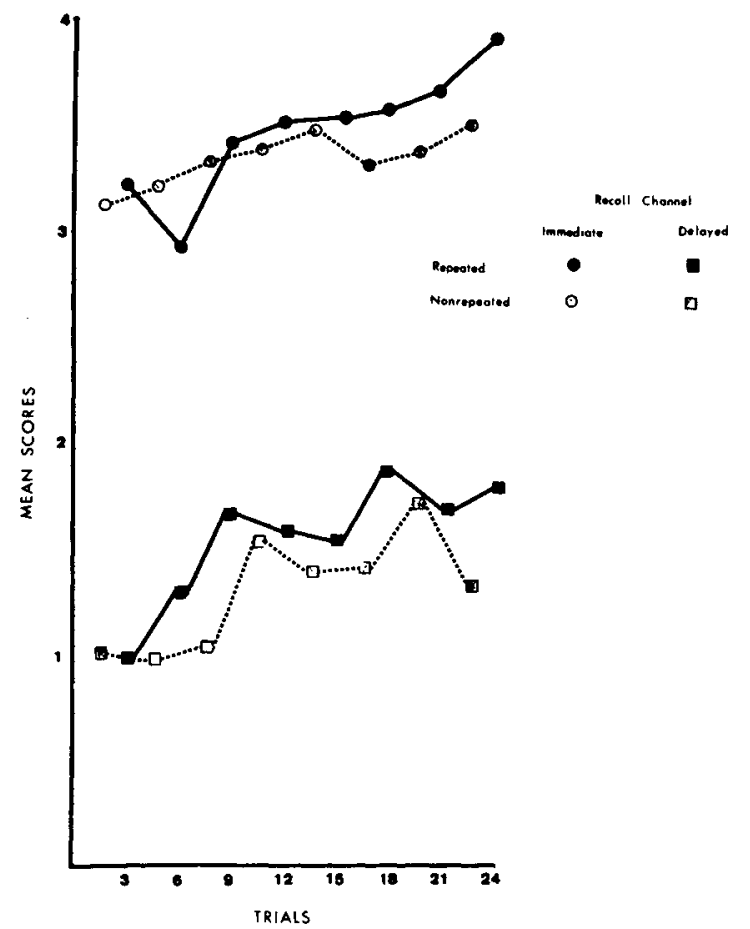

Fig. 1. Mean scores on repeated and non-repeated dichotic digit spans for immediate and delayed channels. Non-repeated digit scores averaged over each pair of interspersed trials.

Hebb's and Melton's findings. There was, however, no significant difference in the way in which the repeated spans changed over trials whether these had been in the immediate or the delayed channel. This finding is not in line with Broadbent's original hypothesis of different processes underlying performance on the two channels and seems to support the alternative view that the same kind of mechanism underlies performance on both channels.

\section{References}

Broadbent, D. E. Immediate memory and simultaneous stimuli. Quart. J. exp. Psychol., 1957, 9, 1-11.

Broadbent, D. E. Perception and communication. New York: Pergamon Press, 1958.

Dirks, D. Perception of dichotic and monaural verbal material and cerebral dominance for speech. Acta Otolaryngol., 1964, 58, 73-80.

Hebb, D. O. The organization of behavior: a neuropsychological theory. New York: Wiley, 1949.

Hebb, D. O. Distinctive features of learning in the higher animal. In J. F. Delafresnaye (Ed.), Brain mechanisms and learning. Oxford: Blackwell, 1961.

Inglis, J. Immediate memory, age and brain function. In A. T. Welford \& J. E. Birren (Eds.), Behavior, aging and the nervous system. Springfield, Ill.: Thomas, 1965.

Inglis, J., \& Ankus, Mary $\mathbf{N}$. Effects of age on st.urt-term storage and serial rote learning. Brit. J. Psychol., 1965, 56, 183-195.

Kimura, Doreen. Cerebral dominance and the perception of verbal stimuli. Canad. J. Psychol., 1961, 15, 166-171.

Melton, A. W. Implications of short-term memory for a general theory of memory. J. verbal Learn. verbal Behav., 1963, 2, 1-21.

\section{Note}

1. This study was made possible by Grant No. HD 02250-01 from the National Institute of Child Health and Human Development. 